\title{
Experimental Study and Application of Process Control on Hot Strip Mill's Laminar Cooling System
}

\author{
Wen-Hong Liu \\ State Key Laboratory of Synthetical Automation of \\ Process Industries, \\ Northeastern University, \\ Shenyang, China \\ E-mail: liuwenhong@ise.neu.edu.cn
}

\begin{abstract}
The performance of hot strip mill depends on the cooling process after hot rolling. One important point of improving the technology of controlled cooling after rolling is understanding the effect of process parameters. Heat transfer coefficient is a significant physical parameter during the cooling process. However, there are a lot of difficulties to solve it directly. In this paper, a mathematical model of inverse heat conduction problem is built and the laminar cooling process is studied by experiment. And then control models and control strategies on hot strip mill's laminar cooling system, including feedforward control and feedback control of coiling temperature with smith predictor, is introduced. They are necessary for the control precision of coiling temperature and have been used on site. And good performance has been got.
\end{abstract}

Keywords-laminar cooling; process control; heat transfer coefficient; feedback control; Smith predictor

\section{INTRODUCTION}

Coiling temperature is one of the important factors which affect the quality of the hot strip. Laminar cooling process is the last process before the finished hot rolling production. This process is very important and it directly decides the quality of the final product [1] [2] [3]. It is impossible that the proper coiling temperature is got by the manual control for highly rolling speed, wide specifications of the products and technical parameters which are often changed [4] [5]. However, automotive control by computers can do it. The automotive control system can get proper coiling temperature, which makes the structure properties and the microstructures of the hot strip satisfactory [6] [7] [8].

Control models and control strategies of the automotive control system are introduced in the following. Coiling temperature control precision has been effectively improved by the application. Fig. 1 shows some equipment diagram of the laminar cooling area. The traditional way of calculating the coefficient which is dependent on empirical formula cannot ensure the precision. Therefore, an experimental study like this is needed.

\author{
Jun-Lin Wang \\ College of Information Science and Engineering, \\ Northeastern University, \\ Shenyang, China \\ E-mail: waterheart666@sina.com.cn
}

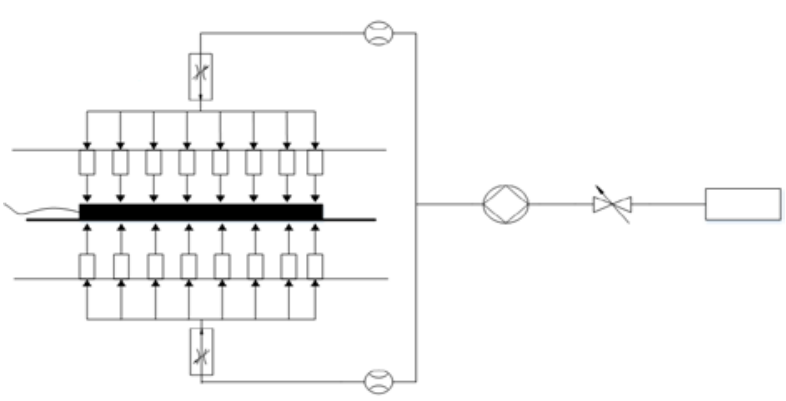

Figure 1. Equipment diagram of laminar cooling area.

Laminar cooling equipment is installed up and down of the roll table between the last finishing mill and the first down coiler. There are a number of groups of laminar cooling headers, in which some groups are used for coarse cooling and the others are for accurate cooling. The coarse cooling area is for the main cooling area and the accurate cooling area is for the feedback control area. The spray mode is laminar flow from the upper U-model headers.

\section{CONREOL MODELS AND CONTROL STRATEGIES}

\section{A. Mathematical Model and Experiment}

In this paper, a mathematical model of inverse heat conduction problem is built and the laminar cooling process is studied by experiment. Fig.2 shows the experiment equipment.

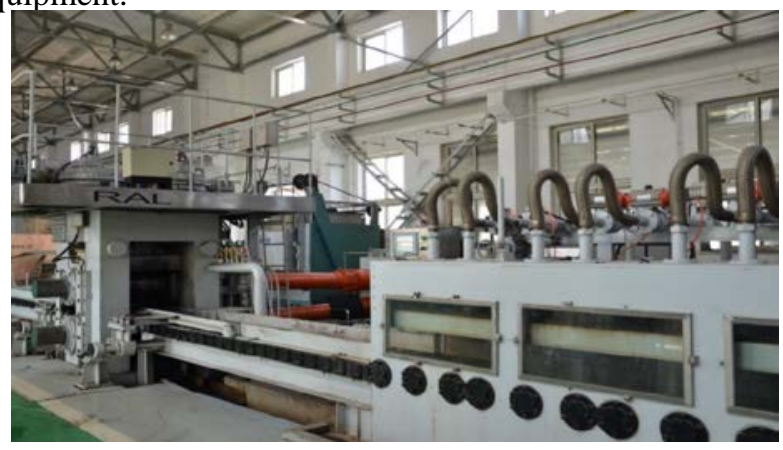

Figure 2. The experiment equipment.

The temperature data of three measure points (point1, point2 and point3) during the laminar cooling process is acquired by thermocouples and the temperature acquisition 
device. The effects of cooling water flow are considered. During experiments, the cooling water flow is changed and the temperature variation is recorded.

A two-dimensional transient heat transfer model is built by finite difference method based on the heavy plate laminar cooling theory. The model of inverse heat conduction problem used Conjugate Gradient Method, Genetic Algorithm and Non-iterative Method are built in MATLAB language.

Fig.3 shows the test specimen and the drilling program. There are three holes in different deeps.

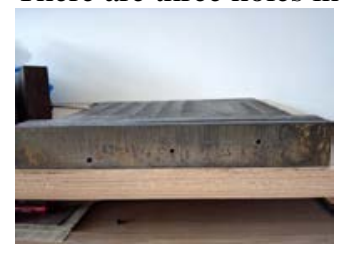

Figure 3. Test specimen and drilling program.

\section{B. Feedback Control with Smith Predictor}

According to temperature deviation between measured value and target value, some headers in accurate cooling area can been dynamically regulated to eliminate the deviation and improve the control precision of the coiling temperature.

The drop of temperature generated by one header can be calculated and transmitted by process computer. The expression is as the following:

$$
N=\operatorname{INT}\left(\Delta T_{f} / \Delta T_{D}+0.5\right)
$$

where $\Delta T_{D}$ is the drop of temperature, $\Delta T_{f}$ is the deviation, and $\mathrm{N}$ is the number to be regulated.

This model is too coarse to be applied. When adopting the PID control model, something is modified as the following:

$\Delta$ Tu can be got if the magnification times of PID is set up by 1; The equation which calculates the final number to be regulated is modified as the following.

$$
N=I N T\left(\alpha \bullet \frac{V_{L}}{V_{M A X}} \bullet \Delta T_{u} / \Delta T_{\mathrm{D}}+0.5\right)
$$

where $\alpha$ is the regulatory factor of feedback control whose range is from 0 to 1 , VL is the actual strip speed $(\mathrm{m} / \mathrm{s})$ and VMAX is the max strip speed $(\mathrm{m} / \mathrm{s})$.

The feedback control system is a typical lag system [9] [10]. So based on PID control, Smith predictor is used for the lag compensation. Fig.4 shows the feedback system with pure lag $\left(1: \mathrm{D}(\mathrm{s}) ; 2: G^{\prime}(s) \bullet e^{-\tau s}\right)$ and Fig.5 shows the modified compensator $\left(1: \frac{K\left(1-e^{-T s}\right)}{s\left(1+T_{1} s\right)} ; 2: e^{-\tau s}\right)$.

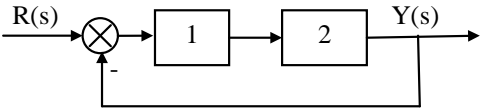

Figure 4. Feedback system with pure lag.

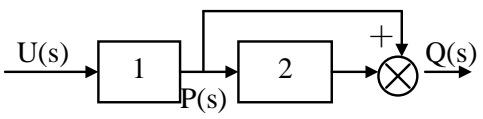

Figure 5. Smith predictor.

In Fig.4, D $\tau(\mathrm{s})$ is the transfer function between $\mathrm{U}(\mathrm{s})$ and $\mathrm{Q}(\mathrm{s})$ :

$$
D_{\tau}(z)=Z\left[\left(D_{\tau}(s)\right]=Z\left|\frac{K\left(1-e^{-T s}\right)}{s\left(1+T_{1} S\right)} \bullet\left(1-e^{-s s}\right)\right|=\left(1-Z^{-1}\right)\left|\frac{b_{1} Z^{-1}}{1-a_{1} Z^{-1}}\right|(3)\right.
$$
number)

where, $\mathrm{a} 1=\mathrm{e}-\mathrm{T} / \mathrm{T} 1, \mathrm{~b} 1=\mathrm{K}(1-\mathrm{e}-\mathrm{T} / \mathrm{T} 1), \mathrm{L} \approx \tau / \mathrm{T}$ (round

$$
D \tau(z)=\frac{Q(z)}{u(z)}=\frac{Q(z)}{P(z)} \cdot \frac{P(z)}{u(z)}=\left(1-z^{-1}\right) \frac{b_{1} z^{-1}}{1-a_{1} z^{-1}}
$$

So the difference equations of $D_{\tau}(\mathrm{s})$ can be got:

$$
\begin{gathered}
\mathrm{P}(\mathrm{k})=\mathrm{a}_{1} \mathrm{p}(\mathrm{k}-\mathrm{L})+\mathrm{b}_{1} \mathrm{u}(\mathrm{k}-\mathrm{L}) \\
\mathrm{q}(\mathrm{k})=\mathrm{p}(\mathrm{k})-\mathrm{p}(\mathrm{k}-\mathrm{L})
\end{gathered}
$$

\section{Feedforward Control after the Finishing Mill Group Throwing Strip}

When the finishing mill group drop strip, the strip speed will vary. And the compensation rate should be calculated.

After the finishing mill group throwing strip, strip speed $\left(V_{\text {ID }}\right)$ is calculated by coiler or pinch roll and spray water configuration from process computer is constant. The equations for feedforward control are as the following:

At the moment when the finish mill group drop strip, the water flow from process computer can generate the drop of the strip temperature $\left(\Delta T_{o l}\right)$ and the equation is as the following:

$$
\Delta T_{O L}=\frac{1000 \times L_{O L}}{3600 \times V_{O L} \times C_{P} \times \gamma \times H F} \times Q_{X F}
$$

After the finish mill group drop strip, the water flow from process computer can generate the drop of the strip temperature $\left(\Delta T_{u D}\right)$ and the equation is as the following:

$$
\Delta T_{M D}=\frac{1000 \times\left(L_{O L}+\Delta L_{M D}\right)}{3600 \times V_{M D} \times C_{P} \times \gamma \times H F} \times Q_{X F}
$$


where $\gamma$ is specific gravity $\left(\mathrm{kg} / \mathrm{m}^{3}\right), C p$ is specific heat $\left(\mathrm{kJ} / \mathrm{kg}^{\circ} \mathrm{C}\right), \quad H F$ is strip thickness $(\mathrm{mm}), V_{M D}$ is actual strip speed after the finishing mill group drop strip $(\mathrm{m} / \mathrm{sec}), V_{O L}$ is strip speed at the moment when the finishing mill group drop strip $(\mathrm{m} / \mathrm{sec}), Q_{X F}$ is coefficient of heat transfer ( $\mathrm{k}$ $\left.\mathrm{J} / \mathrm{m}^{2} \mathrm{~h}\right), L_{O L}$ is the total length of headers at the moment when the finishing mill group drop strip (m), $\Delta L_{M D}$ is the additional length of headers after the finishing mill group drop strip (m), $\Delta T_{O L}$ is the drop of strip temperature the water flow from process computer can generate at the moment when the finishing mill group drop strip $\left({ }^{\circ} \mathrm{C}\right)$, $\Delta T_{M D}$ is the drop of temperature the water flow can generate after the finishing mill group drop strip $\left({ }^{\circ} \mathrm{C}\right)$.

Equate the two equations and the following equation can be deduced:

$$
\Delta L_{M D}=\left(\frac{V_{M D}}{V_{O L}}-1\right) L_{O L}
$$

In this equation, LOL and headers' number are corresponding to each other, so the practical equations can be adopted for compensation:

$$
\begin{aligned}
& \Delta N_{U M D}=2 \alpha\left(\frac{V_{M D}}{V_{O L}}-1\right) N_{U O L} \\
& \Delta N_{D M D}=2 \alpha\left(\frac{V_{M D}}{V_{O L}}-1\right) N_{D O L}
\end{aligned}
$$

where NUOL is the upper headers' number of coarse cooling area from process computer at the moment when the finishing mill group drop strip, NDOL is the down headers' number of coarse cooling area from process computer at the moment when the finishing mill group drop strip, $\triangle \mathrm{NUMD}$ is the additional upper headers' number after the finishing mill group drop strip, $\triangle$ NDMD is the additional down headers' number after the finishing mill

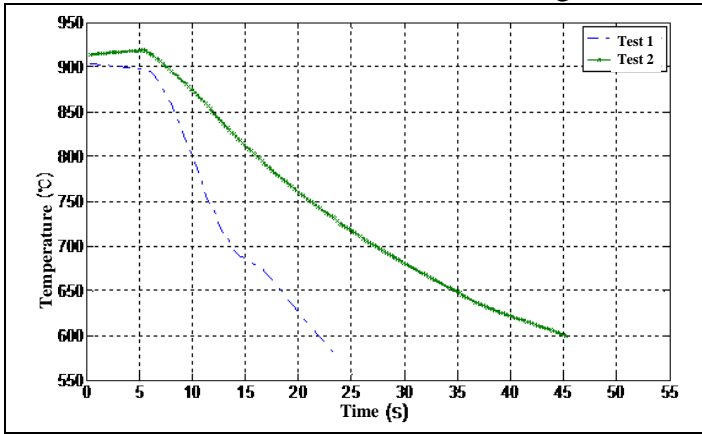

(a) Point 1 temperature curves for two tests group drop strip, and $\alpha$ is the regulatory factor of feedforward control, whose range is from 0.6 to 1 .

\section{APPLICATION AND ANALYSIS}

The process model, control models and control strategies have been successfully applied to the laminar cooling system of some hot strip mill.

\section{A. The Experiment Curves and Analysis}

The water flowrate is $2.35 \mathrm{~m}^{3} / \mathrm{h}$ and $0.95 \mathrm{~m}^{3} / \mathrm{h}$ in test 1 and test 2 . The temperature drop rate of the part closing to the border is seriously affected by adjusting the water flowrate, and the temperature drop rate increases with raising the water flowrate. Relative to the part closing to the border, the temperature drop rate of the part apart from the border is gentle. However, the water flowrate affects the temperature drop rate more or less. Fig.6 shows the temperature curves for two tests.

\section{B. The Temperature Curves and Analysis with or without Feedback Control}

Three pieces of strip in the same batch are rolled separately without feedback, with feedback without Smith predictor and with feedback with Smith predictor, and the temperature curves are as Fig.7 shows. It can be found out that the apparent improvement can be achieved by adopting feedback control and the deviation is less than $20^{\circ} \mathrm{C}$. By comparing the last two curves in Fig.7, it can be concluded that Smith predictor can eliminate the specific lag with feedback control.

\section{The Temperature Curves and Analysis with or without Feedforward Control}

Two pieces of strip in the same batch are rolled separately without feedforward and with feedforward, and the temperature curves are got. It can be found out that the apparent improvement after the finishing mill group dropping strip can be achieved by adopting feedforward control and the deviation is less than $20^{\circ} \mathrm{C}$.

Figure 6. Temperature curves for two tests. 


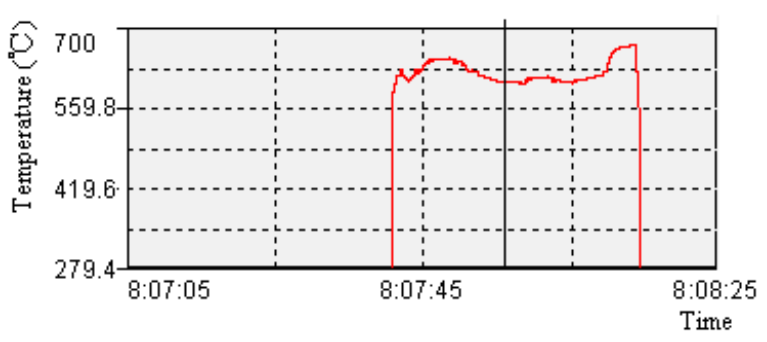

(a) without feedback

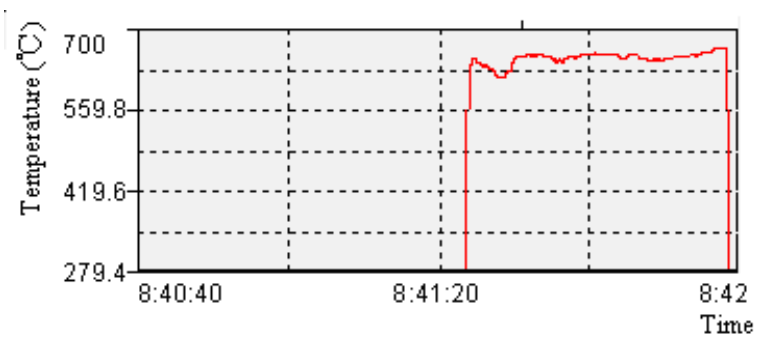

(b) with feedback without Smith predictor

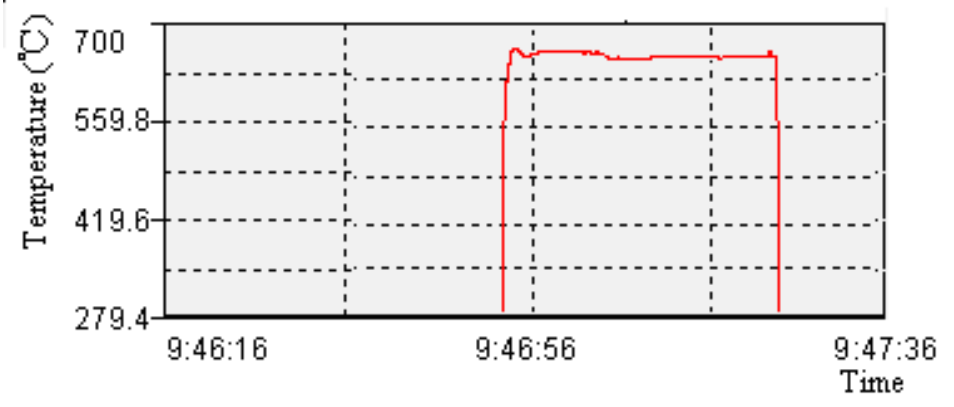

(c) with feedback with Smith predictor

Figure7. Temperature curves of feedback control Steel grade: Q235; set thickness: $4.00 \mathrm{~mm}$; rolling speed: $6700 \mathrm{~mm} / \mathrm{s}$; coiling target temperature: $640 \quad{ }^{\circ} \mathrm{C}$

\section{Synthesis Analysis for Feedback Control and Feedforward Control}

According to analyze a series of temperature curves, it can be concluded that the coiling temperature can be controlled in the ordered range only with feedback control when the change rate of the strip speed is less than or equal to $6 \%$. The coiling temperature can be controlled in the ordered range with feedforward control when the change rate of the strip speed is greater than $6 \%$. It is showed that the head of thin strip is not controlled the same as the head of thick strip, which may be caused by the temperature detector or the cooling disparity and the problem should be studied further.

\section{CONCLUSION}

According to the experimental study and the application of the process control of hot strip mill's laminar cooling, the rationality and effectivity of this system can be certified. And it will be beneficial for further study and application.

\section{ACKNOWLEDGMENT}

The authors would like to thank Professor D. H. Zhang and Professor G. L. Jia for their valuable suggestions and field measure assistance. This project is supported by National Natural Science Foundation of China (61333006 and 61273178).

\section{REFERENCES}

[1] X. N. Wang, X. K. Ding, "Modern strip tandem mill control," Northeastern University Publishing Company, 1996.

[2] H. B. Xie, X. H. Liu, G. D. Wang, "Optimization and model of laminar cooling control system for hot strip mills," Journal of Iron and Steel Research, International, vol. 13, Jan. 2006, pp. 18-22.

[3] M. Samai, T. Loulou, "A comparative Study of Heat Flux and Temperature Based Objective Functional to Solve Inverse Heat Conduction Problems,” Numerical Heat Transfer, vol. 56, Jan. 2009, pp. 75-104.

[4] K. Hamed, K. Farshad, "Solution of inverse heat conduction problem using the lattice Boltzmann method," International Journal of Heat and Mass Transfer, vol. 39, Sep. 2012, pp. 1410-1415.

[5] D. Auzinger, "Recent development in process optimization for laminar cooling in hot strip mills,” Ironmaking and Steelmaking, vol. 23, Jan. 1996, pp. 84-87.

[6] D. Y. Gong, J. Z. Xu, L. G. Peng, "Self-learning and its application to laminar cooling model of hot rolled strip,” Journal of Iron and Steel Research, International, vol. 14, Apr. 2007, pp. 11-15.

[7] K. Z. Omata, H. S. Yoshimura, S. H. Yamamoto, "Leading High Performance Steel Plates with Advanced Manufacturing Technologies,” NKK Technical Review, Aug. 2003, pp.73-80.

[8] K. Yahiro, J. Yamasaki, M. Furukawa, "Development of coiling temperature control system on hot strip mill," Kawasaki Steel Technical Report, vol. 24, Apr. 1991, pp. 32-40.

[9] D. Z. Wang, P. D. Wang, "Super high precision temperature controller with smith predictor for measurement," Journal of Shenyang Institute of Technology, vol. 18, Jan. 1999, pp. 55-59.

[10] S. C. Nisihda, T. S. Matsuoka, T. M. Wada, "Technology and Products of JFE Steefs Three Plate Mills,” JFE Technical Report May. 2005, pp. 1-9. 